\title{
Aurora-A down-regulates IkappaB $\alpha$ via Akt activation and interacts with insulin-like growth factor-I induced phosphatidylinositol 3-kinase pathway for cancer cell survival
}

\author{
Jin-e Yao ${ }^{\dagger 1}$, Min Yan ${ }^{\dagger 1}$, Zhong Guan², Chao-bin Pan ${ }^{3}$, Liang-ping Xia ${ }^{4}$, \\ Chuan-xing Li ${ }^{5}$, Li-hui Wang1, Zi-jie Long1,6, Yan Zhao1, Ming-wei Li ${ }^{1}$, \\ Fei-meng Zheng ${ }^{1}$, Jie $\mathrm{Xu}^{1}$, Dong-jun Lin ${ }^{6}$ and Quentin Liu*1,6
}

\begin{abstract}
Address: ${ }^{1}$ State Key Laboratory of Oncology in South China, Cancer Center, Sun Yat-sen University, 651 Dongfeng Road East, Guangzhou, PR China, ${ }^{2}$ Department of Otorhinolaryngology, Second Affiliated Hospital, Sun Yat-sen University, Yanjiang Road West, Guangzhou, PR China, ${ }^{3}$ Department of Maxillofacial Surgery, Second Affiliated Hospital, Sun Yat-sen University, Yanjiang Road West, Guangzhou, PR China,

${ }^{4}$ Department of Comprehensive, Cancer Center, Sun Yat-sen University, 651 Dongfeng Road East, Guangzhou, PR China, ${ }^{5}$ Department of Medical Imaging \& Interventional Radiology, Cancer Center, Sun Yat-sen University, 651 Dongfeng Road East, Guangzhou, PR China and ${ }^{6}$ Department of Hematology, Third Affiliated Hospital, Sun Yat-sen University, Zhongshan Road, Guangzhou, PR China

Email: Jin-e Yao - yaojine@yahoo.com.cn; Min Yan - yanmin@mail.sysucc.org.cn; Zhong Guan - dr_guanzhong@yahoo.com.cn; Chaobin Pan - docpcb@126.com; Liang-ping Xia - xialiangping@163.com; Chuan-xing Li - lichuanh@mail.sysu.edu.cn; Lihui Wang - wanglihui100@163.com; Zi-jie Long - bio_longzijie@yahoo.com.cn; Yan Zhao - zhaoyan_zs@126.com; Mingwei Li - limingwei2000@163.com; Fei-meng Zheng - mongolia8206@yahoo.com.cn; Jie Xu - xujie_rcl@yahoo.com.cn; Dongjun Lin - liuqlab@yahoo.com; Quentin Liu* - liuq9@mail.sysu.edu.cn

* Corresponding author †Equal contributors
\end{abstract}

Published: 5 November 2009

Molecular Cancer 2009, 8:95 doi:10.1 186/1476-4598-8-95
Received: 2 August 2009

Accepted: 5 November 2009

This article is available from: http://www.molecular-cancer.com/content/8///95

(C) 2009 Yao et al; licensee BioMed Central Ltd.

This is an Open Access article distributed under the terms of the Creative Commons Attribution License (http://creativecommons.org/licenses/by/2.0), which permits unrestricted use, distribution, and reproduction in any medium, provided the original work is properly cited.

\begin{abstract}
Background: The mitotic Aurora-A kinase exerts crucial functions in maintaining mitotic fidelity. As a bona fide oncoprotein, Aurora-A aberrant overexpression leads to oncogenic transformation. Yet, the mechanisms by which Aurora-A enhances cancer cell survival remain to be elucidated.

Results: Here, we found that Aurora-A overexpression was closely correlated with clinic stage and lymph node metastasis in tongue carcinoma. Aurora-A inhibitory VX-680 suppressed proliferation, induced apoptosis and markedly reduced migration in cancer cells. We further showed that insulin-like growth factor-I, a PI3K physiological activator, reversed VX-680-decreased cell survival and motility. Conversely, wortmannin, a PI3K inhibitor, combined with VX-680 showed a synergistic effect on inducing apoptosis and suppressing migration. In addition, Aurora-A inhibition suppressed Akt activation, and VX-680-induced apoptosis was attenuated by MyrAkt overexpression, revealing a cross-talk between Aurora-A and PI3K pathway interacting at Akt activation. Significantly, we showed that suppression of Aurora-A decreased phosphorylated Akt and was associated with increased lkappaB $\alpha$ expression. By contrast, Aurora-A overexpression upregulated Akt activity and downregulated IkappaB $\alpha$, these changes were accompanied by nuclear translocation of nuclear factor- $\kappa \mathrm{B}$ and increased expression of its target gene $\mathrm{Bcl}-\mathrm{xL}$. Lastly, Aurora-A overexpression induced lkappaB $\alpha$ reduction was abrogated by suppression of Akt either chemically or genetically.

Conclusion: Taken together, our data established that Aurora-A, via activating Akt, stimulated nuclear factor$\kappa \mathrm{B}$ signaling pathway to promote cancer cell survival, and promised a novel combined chemotherapy targeting both Aurora-A and PI3K in cancer treatment.
\end{abstract}




\section{Background}

Mammalian Aurora kinases, including Aurora A, B, and C, represent a new family of serine/threonine kinases crucial for several physiological processes including cytokinesis and chromosome segregation [1-3]. Aberrant expression and activity of Aurora kinase lead to formation of abnormal spindle in mitosis and aneuploidy which are closely associated with genomic instability $[1,4]$. Indeed, AuroraA (Aur-A) is frequently overexpressed in various cancer types, such as ovarian, breast, colorectal, pancreatic, bladder and gastric cancer [5-7]. Overexpression of Aur-A induces tumorigenesis, metastasis and chemoresistance, correlating with its pro-survival function in cancer cells. Thus, Aurora kinase has been considered to be an oncoprotein and a promising molecular target for cancer therapy.

We and others previously reported that Aur-A-induced cell survival and migration were correlated with Akt activation $[8,9]$. Phosphatidylinositol 3-kinase (PI3K)/Akt signaling pathway is involved in survival and invasion in human cancers [10-12]. Akt, which consists of a family of highly conserved serine/threonine kinases, plays a key role in mediating insulin-like growth factor-1 (IGF-1)-stimulated cell survival response. Many pro-apoptotic proteins have been identified as direct or indirect Akt substrates, including glycogen synthase kinase-3 (GSK-3), Bad and forkhead transcription factors [13]. In addition, Aur-A was reported to up-regulate NF- $\mathrm{B}$ signaling by phosphorylation of IkappaB $\alpha(I \kappa B \alpha)[14]$. NF- $\kappa B$ stimulates proliferation and blocks apoptosis via modulating transcription of pro-survival genes such as Bcl-xL and Bcl-2 in a number of cancer cell types [15]. Intra-cellular negative regulation of $\mathrm{NF}-\kappa \mathrm{B}$ is controlled primarily through interactions with I $\kappa$ B family, which prevent nuclear translocation and DNA binding of NF- $\kappa \mathrm{B}$. The exact mechanism and pathway by which Aur-A promotes cancer cell survival and anti-apoptosis however remain unclear.

Tongue squamous cell carcinoma (TSCC), the common type of head and neck squamous cell carcinoma, is associated with a high mortality rate. The poor survival of tongue cancer is mainly due to tumor recurrence and regional lymph node metastasis, the most reliable prognostic indicators for patients [16]. Enhanced cytotoxicity has been observed when anti-EGFR monoclonal antibody cetuximab (Erbitux, C225) is used in combination with a number of conventional cytotoxic therapies, including cisplatin and paclitaxel to avoid the severe side-effect. Thus designing new drugs or combined chemotherapy aiming to enhance cytotoxicity and attenuate side-effect becomes urgent and challenging tasks.

In this study, we first showed that Aur-A was overexpressed in TSCC tissues and closely correlated with lymph node metastasis in patients. Aur-A inhibitory VX-680
$[17,18]$ demonstrated a potent anti-tumor activity against various aspects of TSCC tumor progression, offering an opportunity for target therapy. More interestingly, we showed that activation of PI3K signaling by IGF-1 abrogated Aur-A inhibitory VX-680 induced apoptosis, whereas combination of VX-680 and PI3K inhibitor induced synergistic effects on inducing apoptosis and reducing migration in cancer cells. These data suggested a cross-talk between Aur-A and PI3K signaling pathway in regulating cell survival and migration. More importantly, we found that Aur-A downregulated I $\mathrm{B} \alpha \alpha$ via Akt activation, and subsequently induced NF- $\kappa$ B p 65 translocated to nuclei where expression of its target gene $\mathrm{Bcl}-\mathrm{xL}$ was increased, pointing that Aur-A promoted cell survival via Akt-mediated I $\kappa \mathrm{B}$ kinase (IKK)/NF- $\kappa \mathrm{B}$ signaling pathway. Taken together, understanding the mechanism underlying the pro-survival activity of Aur-A and the link between Aur-A and PI3K pathway provide a new insight and rationale for future combined molecular targeting therapeutics.

\section{Results}

Aur-A is overexpressed in TSCC tissues and correlated with clinical stage and lymph node metastasis

We used the immunohistochemical analysis to investigate Aur-A expression in primary tumor tissues. Results showed that only a few $(7 / 30,23.3 \%)$ matched adjacent normal tissues displayed Aur-A positive staining (Fig. 1a). However, Aur-A was significantly elevated in majority $(36 / 55,65.5 \%)$ of pathologically confirmed tumor specimens (Fig. 1b). Aur-A was uniformly cytoplasmic positive staining, uncoupled with its normal mitosis-related expression pattern.

We further analyzed the relationship between Aur-A expression and clinical characteristics (Table 1). Aur-A was more frequently expressed in high-grade tumors (stage III and IV, 77.8\%) compared with low-grade (stage I and II, 42.1\%) tumors $(p=0.008)$. Moreover, we observed preferential expression of Aur-A in tumor with positively ( $87.5 \%$ ) versus negatively (56.4\%) lymph node metastasized samples $(p=0.028)$. No significant correlation was found between Aur-A expression and other clinical characteristics including age, gender and differentiation status. Thus, the potential association between tumor overexpression of Aur-A and clinic stage or lymph node metastasis raises the possibility of specific inhibition of Aurora kinase in treatment of tongue cancer cells.

\section{Aurora kinase inhibitory VX-680 suppresses cell growth and induces apoptosis in a dose-dependent manner in TSCC cells}

To evaluate the inhibition of Aurora kinase in TSCC cells, we used a small molecule inhibitor VX-680. Figure 2a showed that the percentage of abnormal spindle as was 
a

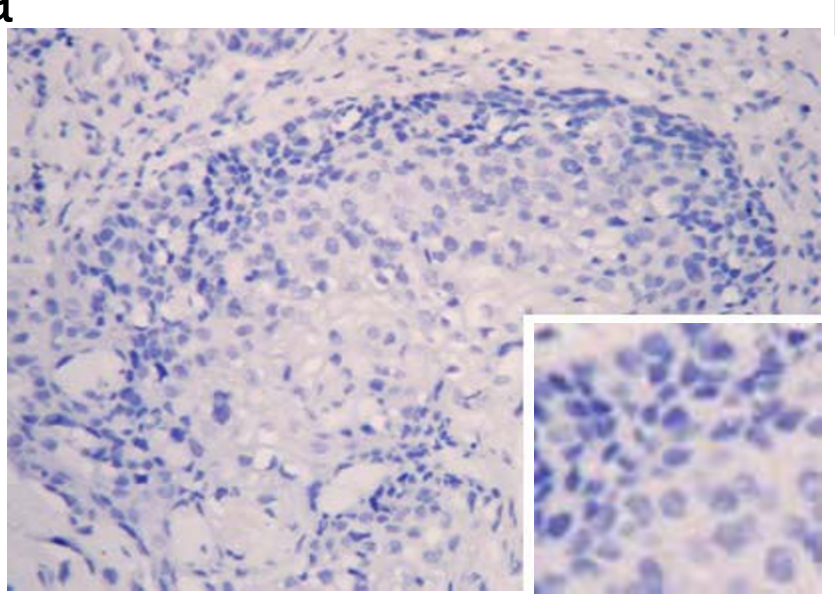

b

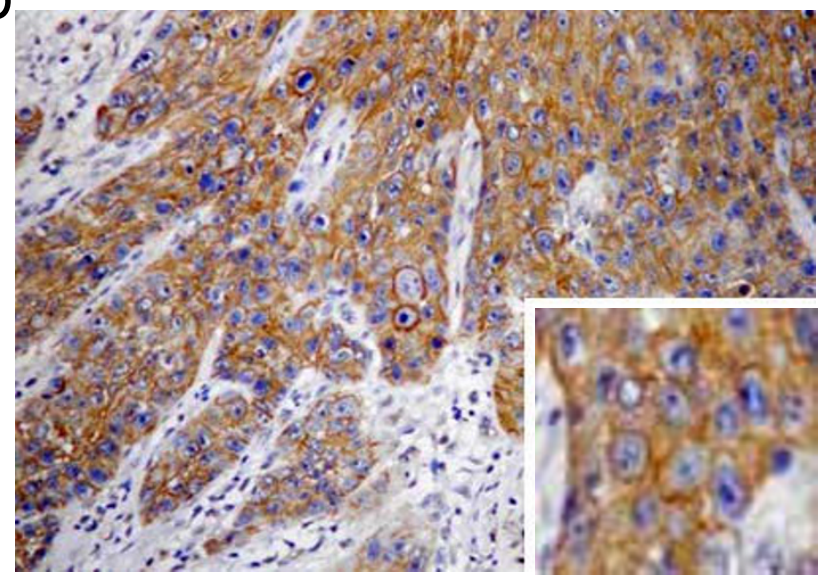

Figure I

Aur-A is overexpressed in TSCC tissues and correlated with clinical stage and lymph node metastasis. TSCC or its corresponding adjacent normal samples were collected and subjected to immunohistochemical staining with Aur-A antibody. (a) Aur-A expression is low in normal samples. (b) Aur-A expression is obviously increased in TSCC, original magnification, $\times 200$. Insets show enlarged views, original magnification, $\times 400$.

markedly increased in VX-680 treated mitotic cells (22.39 $\pm 0.98 \%)$ compared to the control mitotic cells (4.21 \pm $0.91 \%$ ). The abnormal spindle characterized as monopolarity consistent with a known Aur-A inhibition phenotype [19]. Phosphorylation inhibition of histone H3 at Ser10, an in vivo substrate of Aur-B was significantly reduced in Tca8113 cells treated with VX-680 at $1 \mathrm{nM}$ $(12.00 \pm 3.06)$ or $5 \mathrm{nM}(5.80 \pm 0.08)$, compared to the control cells ( $30.20 \pm 8.62$, Fig. 2b).

Cell survival rates were reduced by VX-680 in a dosedependent manner as assessed by MTT assay with $\mathrm{IC}_{50}$ of $6.45 \pm 1.14 \mathrm{nM}$ (Fig. 2c). Annexin $\mathrm{V}$ assay revealed that VX-680 induced apoptosis even at $1 \mathrm{nM}$ as showed in Annexin V and PI staining positive (Fig. 2d). Western blot assay showed that VX-680 reduced the expression of antiapoptotic protein Bcl-2 and increased the level of both cleaved PARP and cleaved caspase- 3 in a dose-dependent manner (Fig. 2e). Caspase-3 inhibitor however reversed $\mathrm{Bcl}-2$ reduction and PARP cleavage in response to VX-680 (data not shown).

\section{Cross-talk between Aur-A and PI3K pathway regulates VX- 680 induced apoptosis in tumor cells}

Using a serum-free system, we examined cell apoptosis by Western blot and flow cytometry assay. IGF-1 increased the phosphorylation of Akt at Ser473 and its downstream target GSK3 at Ser 21/9. Expression of IкB $\alpha$ was however decreased by IGF-1 treatment (Fig. 3a), which also prevented VX-680 (5 nM)-induced apoptosis (Fig. 3b). Inter-

Table I: Association of Aur-A expression with clinicopathological parameters

\begin{tabular}{|c|c|c|c|c|c|}
\hline Clinicopathological features & & $\mathbf{n}$ & $\begin{array}{l}\text { Aur-A expression } \\
\text { Positive No.(\%) }\end{array}$ & $\chi^{2}$ & $P$ \\
\hline \multirow[t]{2}{*}{ Age } & $\leq 60$ years & 28 & $20(71.4)$ & 0.900 & 0.343 \\
\hline & $>60$ years & 27 & $16(59.3)$ & & \\
\hline \multirow[t]{2}{*}{ Gender } & Male & 33 & $22(66.7)$ & 0.054 & 0.817 \\
\hline & Female & 22 & $14(63.6)$ & & \\
\hline \multirow[t]{2}{*}{ Clinical Stage } & $1+\|$ & 19 & $8(42.1)$ & 6.999 & 0.008 \\
\hline & III+IV & 36 & $28(77.8)$ & & \\
\hline \multirow[t]{3}{*}{ Differentiation } & Well & 7 & $2(28.6)$ & 4.952 & 0.084 \\
\hline & Moderate & 26 & $19(73.1)$ & & \\
\hline & Poor & 22 & $15(68.2)$ & & \\
\hline \multirow[t]{2}{*}{ Lymph node metastasis } & Positive & 16 & $14(87.5)$ & 4.850 & 0.028 \\
\hline & Negative & 39 & $22(56.4)$ & & \\
\hline
\end{tabular}


a

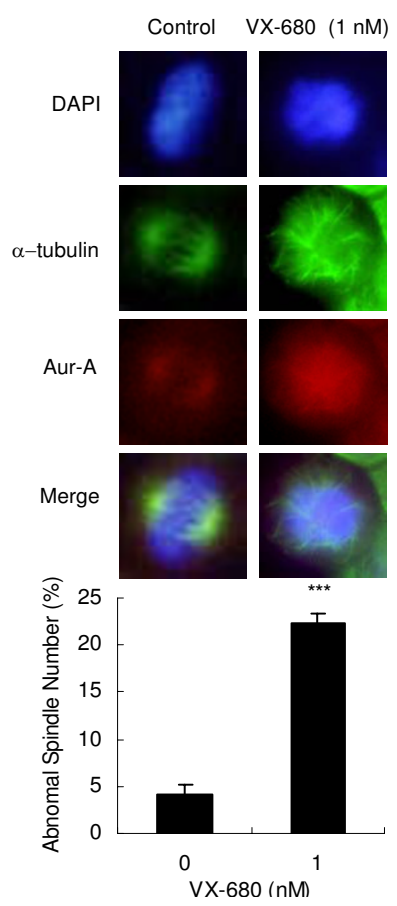

C

e

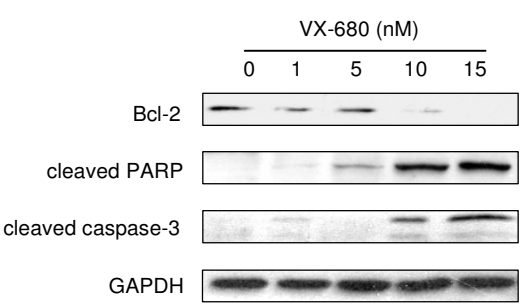

b
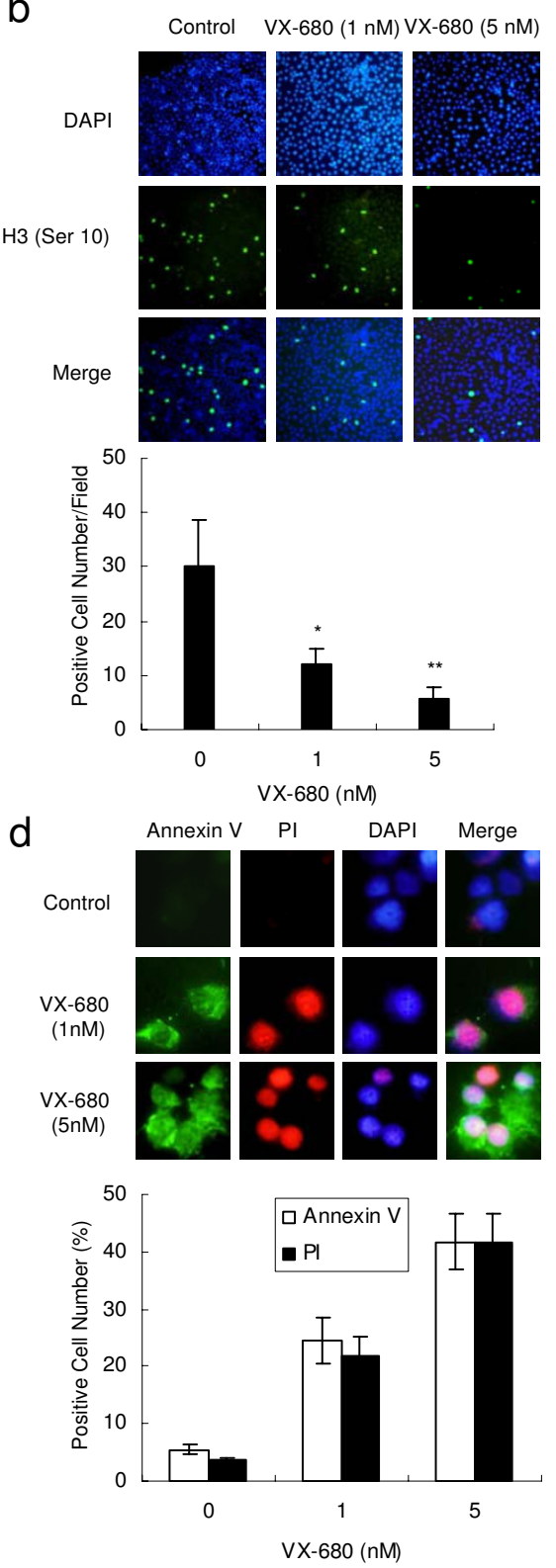

\section{Figure 2}

Aurora kinase inhibitory VX-680 suppresses cell growth and induces apoptosis in TSCC cells. Cells were maintained at DMSO (served as a control) or VX-680 for $48 \mathrm{~h}$. (a and b) VX-680 inhibits Aurora kinase and leads to defects in mitotic spindles. Cells were subjected to immunofluorescence staining with $\alpha$-tubulin (green), Aur-A (red, original magnification $\times 600$ ) or pHistone H3-Ser 10 antibodies (green, original magnification $\times 200$ ). DAPI (blue) was used to visualize the nuclei. (a) Quantification showed the percentage of the abnormal spindles assessed as monopolarity of three independent experiments. In each experiment, at least 150 randomly chosen spindles were counted. (b) Histogram indicated the number of pHistone $\mathrm{H} 3$ positive cells counted in five randomly selected fields from three independent experiments. Error bars indicated the SD. ${ }^{*} p<0.05$, **p $<0.01$, compared to control. (c-e) VX-680 suppresses cell growth and induces apoptotic cell death. (c) Cell survival rates were measured by MTT assay, ${ }^{*}<<0.05$, ***p $<0.00 \mathrm{I}$. (d) Representative immunofluorescent images of apoptotic cells were stained with Annexin V (green), PI (red) and DAPI (blue). Histogram represented the percentage of Annexin V or PI positive staining cells of three independent experiments. (e) Cell apoptosis was analyzed by Western blot with indicated antibodies. GAPDH was used as a control. 
a

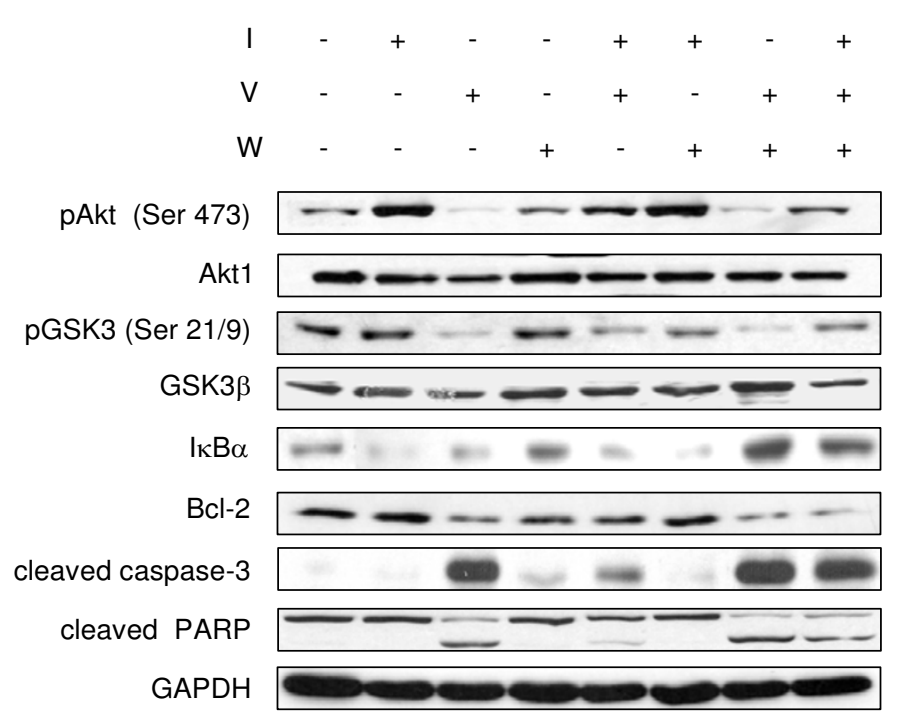

b

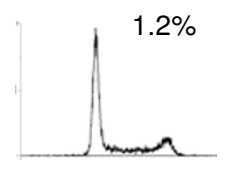

Control

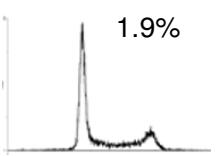

I+V

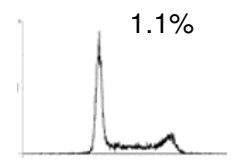

I

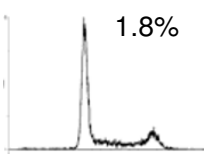

I+W

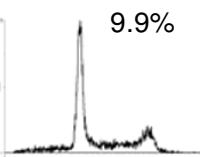

V

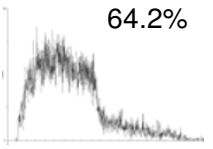

$\mathrm{V}+\mathrm{W}$

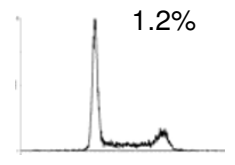

W

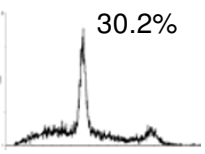

$\mathrm{I}+\mathrm{V}+\mathrm{W}$

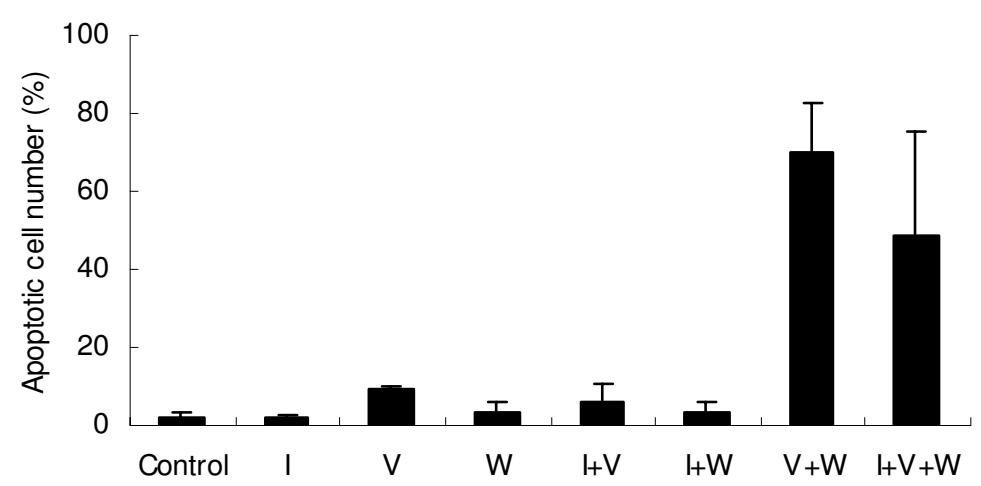

Figure 3

Cross-talk between Aur-A and PI3K pathway regulates VX-680 induced apoptosis in TSCC cells. Serum-starved Tca8I I 3 cells treated with IGF-I (I, I00 ng/ml), wortmannin (W, I $\mu \mathrm{M}), \mathrm{VX}-680$ (V, $5 \mathrm{nM}$ ) alone or in combination for I $2 \mathrm{~h}$. (a) Cells were subjected to Western blot analysis with indicated antibodies. GAPDH was used as a control. (b) The apoptosis was assessed by flow cytometry as a sub-GI population. Images showed one representative of three independent experiments. Histogram represented the quantification. 
estingly, VX-680 and an irreversible PI3K inhibitor wortmannin in combination displayed a dramatic effect in inhibiting Akt and GSK3 activity, elevating IкB $\alpha$ expression (Fig. 3a), and increasing cell apoptosis, compared with either VX-680 (about 7.90 \pm 2.54 -fold) or wortmannin (about $18.49 \pm 2.88$-fold) alone (Fig. 3b). We calculated the cooperative coefficient of VX-680 and wortmannin was $6.09 \pm 0.35$, suggesting wortmannin synergized VX-680 mediated apoptosis by inhibiting PI3K. Meanwhile, elevated levels of cleaved PARP and cleaved caspase-3 and reduction of $\mathrm{Bcl}-2$ expression were observed in cells treated with VX-680 and/or wortmannin (Fig. 3a). These data together indicated that there was an intracellular cross-talk between Aurora kinases and PI3K pathway in regulating cancer cell survival. We conducted Western blot with another squamous carcinoma KB cells and observed similar results (Additional file 1).

\section{Aur-A interacts with PI3K pathway in regulating TSCC cell migration}

We have showed that overexpression of Aur-A was positively correlated with lymph node metastasis (Table 1), and cell migration was closely associated with potential of tumor invasiveness and metastasis. We showed that VX680 potently induced a dose-dependent inhibition in the migration of Tca8113 cells (Additional file 2). Similar inhibition of cell motility was also induced by Akt/protein kinase B signaling inhibitor-2 (API-2) at dose of $1 \mu \mathrm{M}$.

We then conducted the transwell migration assay in serum-free condition. Compared with the control cells, IGF-1 significantly enhanced migration of Tca8113 cells (about 3.5-fold), while either VX-680 or wortmannin alone at low dose could partially reduce the cell mobility induced by IGF-1 (Fig. 4). Moreover, the combination of VX-680 and wortmannin efficiently abrogated IGF-1 induced cell migration in a synergic manner. Meanwhile we performed MTT assay to detect the cell viability in the same system. These results showed that the suppression of migration by VX-680 and/or wortmannin were not due to inducing apoptosis in Tca8113 cells (data not shown). Thus, these data indicated the interaction between Aurora kinases and PI3K pathway also played a key role in cancer cell migration.

\section{Activated Akt attenuates Aur-A inhibitory VX-680-induced apoptosis in TSCC cells}

Based on above findings, we hypothesized that Aur-A and PI3K pathway might interact at Akt. The level of pAkt was decreased in cells treated with increasing concentration of VX-680 (Fig. 5a). We further overexpressed a constitutively active form of Akt (Myr-Akt1) in Tca8113 cells (Fig. 5b). MTT assay showed that the survival rate of Myr-Akt1 transfected cells was $(46.43 \pm 7.95 \%$ and $38.11 \pm 6.16 \%)$, obviously higher than that of empty vector pUSE trans- a

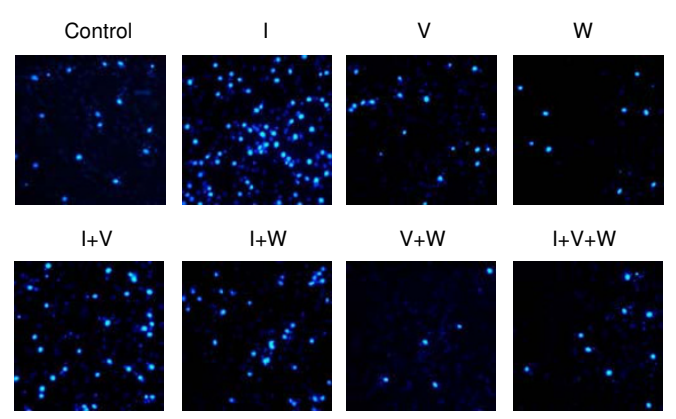

b

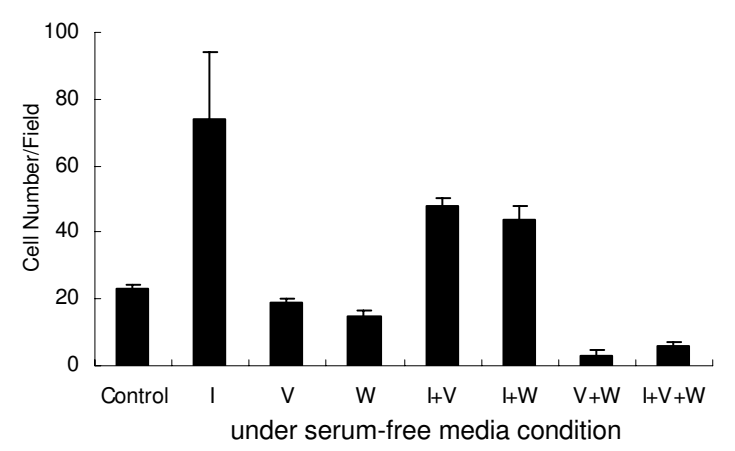

Figure 4

Aur-A interacts with PI3K pathway in regulating TSCC cell migration. Cells were incubated in serum-free media containing IGF-I (I, $100 \mathrm{ng} / \mathrm{ml})$, wortmannin $(\mathrm{W}, \mathrm{I}$ $\mu M), V X-680(V, I \mathrm{nM})$ alone or in combination for $16 \mathrm{~h}$. Migration rates were quantified by counting the migrated cells in five random fields. (a) One representative of three independent experiments was shown, original magnification $\times 200$. (b) Data summarized three independent experiments in identical condition.

fected cells $(31.5 \pm 1.67 \%$ and $18.93 \pm 2.90 \%)$ when treated with VX-680 at $5 \mathrm{nM}$ and $10 \mathrm{nM}$ respectively (Fig. 5c). We performed Aur-A RNAi in vector or Myr-Akt 1 transfected cells and observed similar results (Additional file 3). Together, these data suggested that Akt was a potential downstream target of Aurora kinases in enhancing cancer cell survival.

\section{Aur-A down-regulates $I_{k} B \alpha$ via Akt phosphorylation and induces $p 65$ subunit of NF- $K B$ nuclear translocation}

A recent study reported that Aur-A regulated NF- $\mathrm{BB}$ via

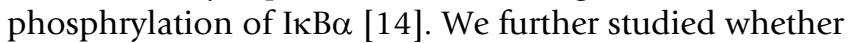
Aur-A regulated I $\mathrm{B} \alpha$ and its downstream targets via Akt pathway. Decreased pAkt and elevated IкB $\alpha$ were detected when cells were transfected with siRNA toward either Akt (Additional file 4) or Aur-A (Fig. 6a), compared with cells transfected with their scramble control respectively. Inhi-

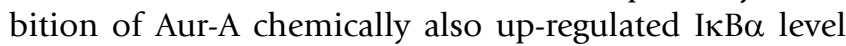


a

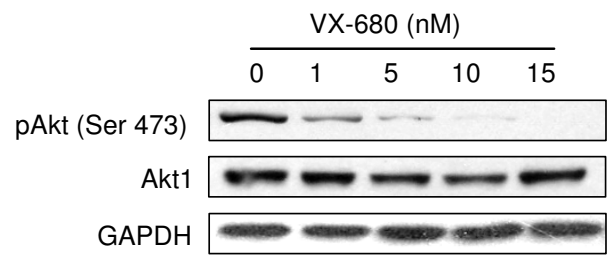

b

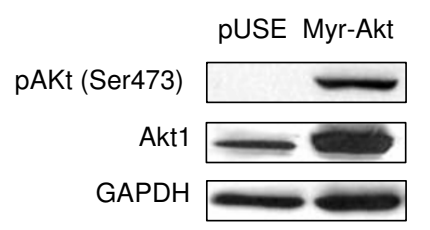

C

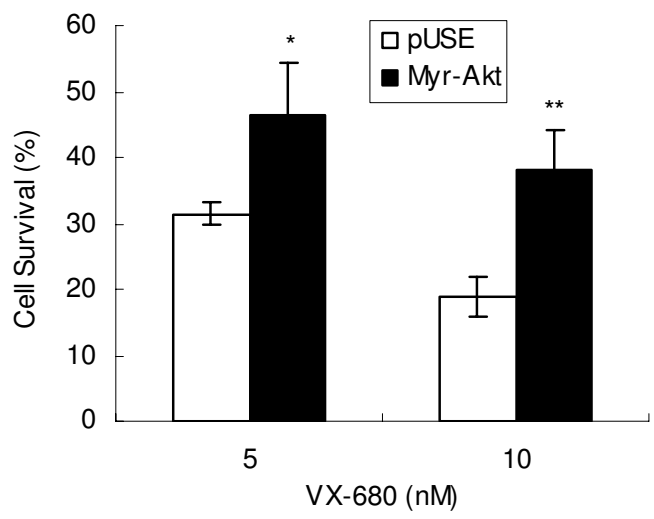

\section{Figure 5}

Activated Akt attenuates Aur-A inhibitory VX-680induced apoptosis in TSCC cells. (a) Cells were incubated in serum-free media with indicated doses of VX-680 for $24 \mathrm{~h}$, and subjected to Western blot analysis with pAkt (ser473), and Aktl antibodies. (b) Myr-Aktl or pUSE stable transfected cells were subjected to Western blot with pAkt and Aktl antibodies, GAPDH was used as a control. (c) MyrAkt l or pUSE transfected cells were treated with VX-680 (5 $\mathrm{nM}$ or $10 \mathrm{nM}$ ) for $24 \mathrm{~h}$. Cell survival rates were measured by MTT assay.

(Fig. 6b). Conversely, overexpression of Aur-A increased Akt activity and decreased $\mathrm{I} \kappa \mathrm{B} \alpha$ level compared with the vector control (Fig. 6a). We then analyzed the expression of $\mathrm{Bcl}-\mathrm{xL}$, which is known as a NF- $\kappa \mathrm{B}$ target gene closely associated with cell proliferation and apoptosis. Bcl-xL was down-regulated in Aur-A and Akt depleted cells (Fig. 6a). Immunofluorescence staining of NF- $\mathrm{B}$ p 65 showed that Aur-A overexpression was significantly associated with p65 nuclear translocation whereas p65 was mainly expressed in the cytoplasm in cells transfected with empty vector pCS2+ (Fig. 6c). We further showed that inhibition of PI3K with wortmannin did not prevent either an increase of pAkt and Bcl-xL or a decrease in $\mathrm{I} \kappa \mathrm{B} \alpha$ caused by Aur-A overexpression (Fig. 6d). Interestingly, in cells incubated with Akt inhibitor API-2 or siRNA against Akt, overexpression of Aur-A however failed to reduce $\mathrm{I} \kappa \mathrm{B} \alpha$ or raise $\mathrm{Bcl}-\mathrm{xL}$ expression in comparison to the vector control (Fig. Ge and 6f). This suggested that Akt, but not PI3K, was involved in the down-regulation of I $\kappa \mathrm{B} \alpha$ by Aur-A. These results revealed that Aur-A, via its downstream target Akt, down-regulated $\mathrm{I} \kappa \mathrm{B} \alpha$, which then led to NF- $\kappa \mathrm{B}$ nuclear translocation and subsequently activating NF- $\kappa \mathrm{B}$ target gene Bcl-xL in enhancing cancer cell survival (Fig. 6g).

\section{Discussion}

Aur-A kinase plays a critical role in tumorigenesis as an oncogenic protein. However, the exact pathway by which Aur-A enhances cell survival has not been well defined. In this study, we showed that Aur-A, via activating Akt pathway, induced NF- $\kappa \mathrm{B}$ nuclear translocation to promote cell survival. Indeed, overexpression of Aur-A was positively associated with clinic stage and lymph node metastasis in TSCC patients. Moreover, we established a cross-talk between mitotic Aurora kinase and IGF-1-induced PI3K survival pathway, interacting at Akt activation. Combined inhibition of both Aur-A and PI3K led to a synergistic effect on inducing apoptosis and suppressing migration, reassuring an emerging theme of combination therapy in cancer treatment.

Aur-A, a key regulator of mitosis, is essential for centrosome function, spindle assembly, and mitotic entry [1-3]. Dysregulation of Aur-A has been linked to tumorigenesis. Previous studies have also shown that Aur-A functions as a pro-survival protein that counteract apoptosis and induce drug resistance in tumour cells [20]. We and others demonstrated that Aur-A promoted cell survival and migration by Akt activation, and Aur-A activated NF- $\kappa$ B via I $\mathrm{B} \alpha$ phosphorylation $[8,9,14]$. Nevertheless, a clear pathway from Aur-A activation to cell survival remains to be elucidated. In this study, we showed that inhibition of Aur-A induced cell apoptosis accompanied with suppressing Akt activation, increasing $\mathrm{I} \kappa \mathrm{B} \alpha$ level and down-regulating $\mathrm{Bcl}-\mathrm{xL}$ expression. On the contrary, overexpression of Aur-A led to Akt activation and $\mathrm{I} \kappa \mathrm{B} \alpha$ down-regulation, subsequently induced NF- $\kappa$ B p 65 nuclear translocation to enhance cell survival. Moreover, suppression of Akt by

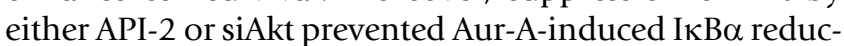
tion and Bcl-xL elevation. Thus, our data demonstrated that Aur-A downregulated I $\mathrm{B} \alpha$ via Akt activation, triggering NF- $\kappa \mathrm{B}$ p 65 nuclear translocation, and subsequently activating target gene Bcl-xL to promote survival in cancer cells.

Inactivation of PTEN leads to constitutively activate PI3K/ Akt pathway. Recently, Aur-A was found to abrogate the DNA-binding and transactivation activity of p53 and sub- 
a

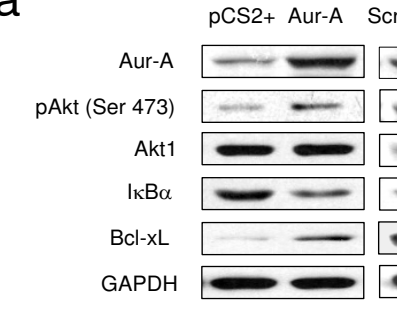

C

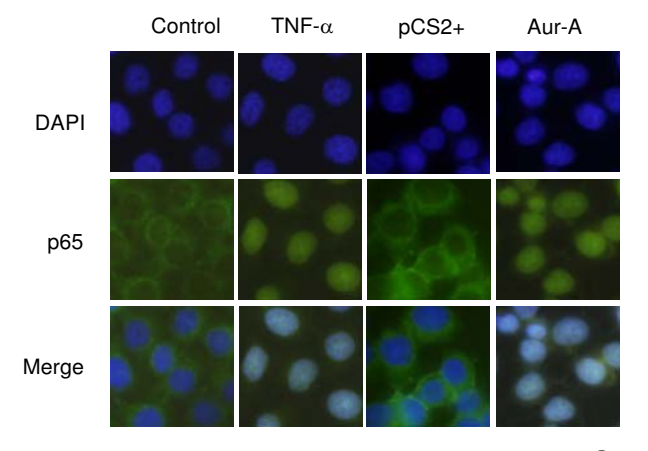

d

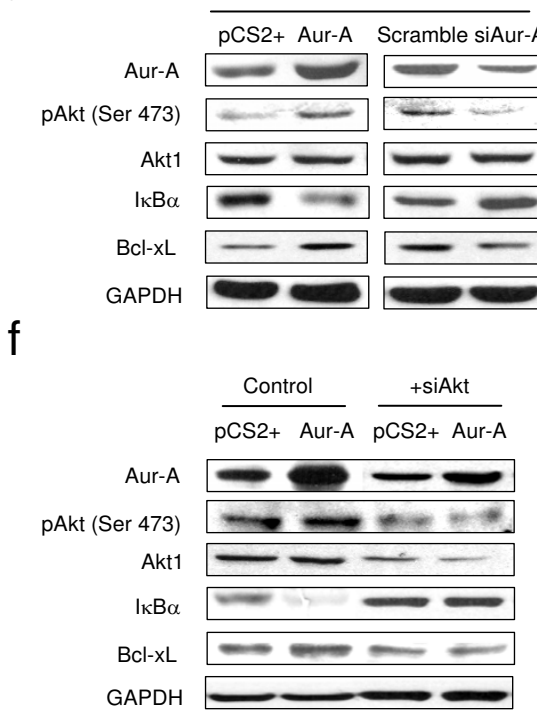

b
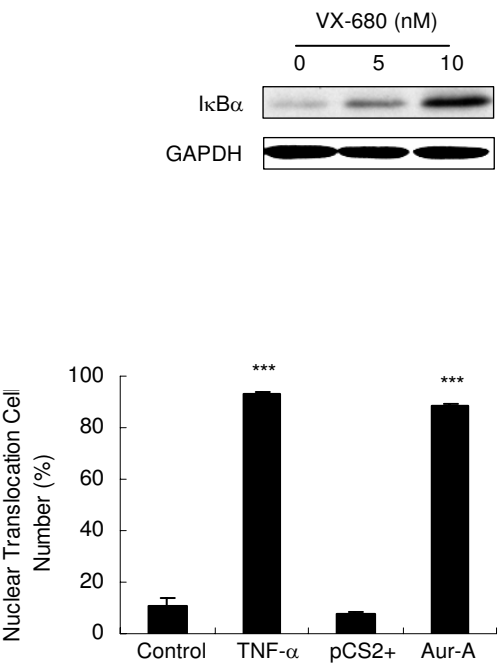

e

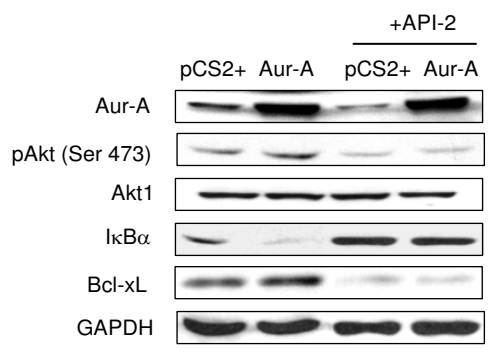

9

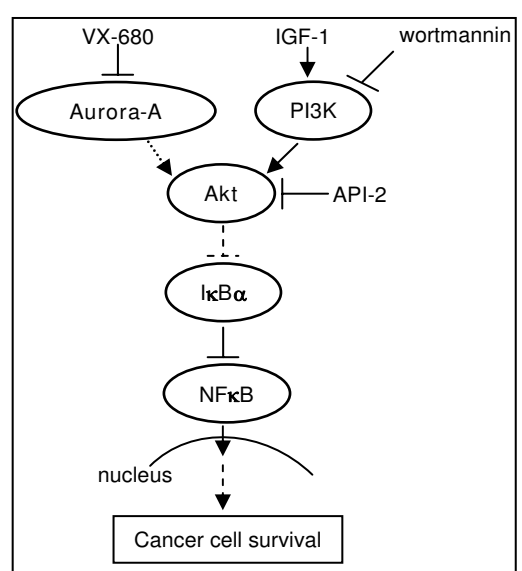

Figure 6

Aur-A down-regulates I $\mathrm{B} \alpha$ via Akt phosphorylation and induces p65 subunit of NF- $\kappa B$ nuclear translocation. (a) Cells were transiently transfected with Aur-A or pCS2+, or Aur-A siRNA or its scramble control. (b) Cells were incubated in serum-free media with VX-680 for $12 \mathrm{~h}$. (c) Cells were treated with or without TNF- $\alpha 50 \mathrm{ng} / \mathrm{ml}$, or transiently transfected with Aur-A or pCS2+, and subjected to immunofluorescence staining with anti-p65 antibody (green). DAPI (blue) was used to visualize the nuclei, original magnification $\times 1000$. Histogram represented the percentage of cells with nuclear translocation from three independent experiments. (d) Aur-A or pCS2+, Aur-A siRNA or its control transfected cells treated with wortmannin I $\mu \mathrm{M}$ for $24 \mathrm{~h}$ before harvesting. (e) Cells were transfected with Aur-A or pCS2+ and treated with API-2 I $\mu \mathrm{M}$ for 24 $\mathrm{h}$ prior to harvesting. (f) Cells were cotransfected Aur-A or pCS2+ with Akt I siRNA or its control. Cell lysates were analyzed for indicated proteins by Western blot ( $\mathrm{a}, \mathrm{b}$ and $\mathrm{d}-\mathrm{f})$. (g) A diagram depicts the Aur-A-mediated pro-survival signaling pathways. 
sequently inhibit its downstream target genes including PTEN by phosphorylating Ser 215 [21]. PTEN expression was significantly reduced in Aur-A overexpressed cells with activated Akt activity [22]. Here, we showed that overexpression of Aur-A increased the phosphorylation of Akt at Ser 473 (Fig. 6a). Consistently, previous report showed that Aur-A activated Akt in a p53-dependent manner to induce cell survival and chemoresistance in ovarian cancer cells [9]. Thus, it is conceivable that Aur-A activates Akt via inhibiting PTEN.

Akt promotes cell survival by its ability to phosphorylate and inactivate several pro-apoptotic targets including GSK-3. We showed that inhibition of Aur-A resulted in suppressed phosphorylation of both Akt and GSK-3, according with one recent study that Aur-A promoted cell proliferation by increasing the phosphorylation of GSK$3 \beta$ [23]. On the other hand, another work reported that Akt inhibitor A-443654 interfered with mitotic progression by decreasing Aur-A expression, suggesting Akt acts upstream of Aur-A by regulating its transcription level [24]. We and others showed that Aur-A contributed to cell survival, chemoresistance and migration via activation of Akt, suggesting a positive feedback interplaying between Aur-A and Akt.

Akt plays a part in activation of NF- $\kappa \mathrm{B}$ signaling pathway and exerts a positive effect on NF- $\kappa \mathrm{B}$ function by phosphorylation and activation of IKK, a kinase that phosphorylates and induces proteolytic degradation of the NF- $\kappa \mathrm{B}$ inhibitor, $\mathrm{I} \kappa \mathrm{B} \alpha[25]$. Interestingly, several recent reports have suggested that Aur-A kinase may serve both upstream and downstream of the IKK complex components $[14,26]$. IKK complex includes two catalytic components, IKK $\alpha$ and IKK $\beta$. As a downstream target, Aur-A was phosphorylated by IKK $\alpha$ at threonine residue 288, a site which is important for its kinase activity [26]. Depletion of IKK $\beta$ resulted in the up-regulation of Aur-A protein, and IKK $\beta$ functioned as an antagonist of Aur-A signaling during mitosis in normal cells [27]. On the other hand, we showed that Aur-A promoted cell survival through activated IKK/NF- $\kappa \mathrm{B}$ signaling pathway, consistent with previous reports $[14,28]$. Thus, there may be a reciprocal regulation between Aur-A and IKK complex.

Activation of Akt was associated with adverse outcome in tongue cancer patients, serving as a significant prognostic factor in TSCC [29]. Multiple growth factors such as IGF$1, \mathrm{VEGF}$, and EGF facilitate the development and progression of cancer by activating PI3K pathway leading to cell survival and therapeutic resistance [30-32]. Here, we showed that Aur-A was overexpressed in tongue cancer tissue and tightly correlated with clinical stage and lymph node metastasis in patients (Fig. 1 and Table 1). Thus, dysregulation of mitotic Aur-A kinase and abnormal activa- tion PI3K survival pathway are two essential but distinct biological processes in cancer progression. As tumorigenesis is a multiple process, combination therapeutic strategies have shown substantially enhanced anti-tumor effects and reduced side-effects both in vitro and in vivo. A recent study reported that combined treatment with the pan-histone deacetylase inhibitor vorinostat and Aur-A kinase inhibitor MK-0457 (VX-680) showed a synergistic anti-leukemia activity in cultured and primary AML and CML cells [33]. Here, we demonstrated that Aur-A inhibitory VX-680 could markedly reduce IGF-1 induced survival and migration. Furthermore, combinational inhibition of Aur-A and PI3K showed a synergic effect in causing apoptosis and suppressing migration in cancer cells (Fig. 3, 4 and Additional file 1).

\section{Conclusion}

Taken together, our findings demonstrated that Aur-A stimulated NF- $\kappa B$ signaling pathway via Akt activation to promote cancer cell survival, and formed a conceptual basis for the combination chemotherapy of targeting both Aurora kinase and growth factor-induced PI3K pathway for inhibiting the enhanced survival and migration of cancer cells.

\section{Methods}

\section{Patients and clinical tissue specimens}

Fifty-five patients who performed radical surgery were original clinically diagnosed and pathologically confirmed of TSCC between 1987 and 1992. Pertinent patient clinical reports were obtained with prior patient consent and the approval of the institutional Clinical Ethics Review Board. All of the 55 specimens and additional 30 normal adjacent tissues were collected and fixed in formalin and embedded in paraffin in the diagnostic histopathology laboratory at the Second Affiliated Hospital of Sun Yat-sen University. Patient clinic pathological features were shown in Table 1. Tumors were staged according to UICC classification (1997): stage I (4 cases), II (15 cases), III (23 cases) and IV (13 cases) or histopathology classification: stage I ( 7 cases) stage II (26 cases) and stage III (22 cases).

\section{Reagents and cell lines}

VX-680 was purchased from Kava Technology, San Diego, CA., API-2 was from Calbiochem, IGF-1 from Biosource, tumor necrosis factor $\alpha$ (TNF- $\alpha$ ) and wortmannin from Cell Signaling. Human tongue squamous cancer cell line Tca8113 was kindly provided by Xiao-feng Zhu (Cancer Center, Sun Yat-sen University), human oral floor cancer cell line KB was obtained from ATCC.

\section{Immunohistochemical staining of Aur-A expression}

Aur-A immunohistostaining using an anti-Aur-A antibody (Upstate) on tongue cancer tissues was performed as pre- 
viously described [8]. Moderate or strong cytoplasm staining, considered as positive reaction, was assessed semiquantitatively by at least two independent pathologists. Specimen was determined as positive staining for Aur-A when $>30 \%$ cells showed visible brown granules in the cytoplasm.

\section{Immunofluorescence staining}

Cultured cells grown on coverslips treated with DMSO or VX-680, or transiently transfected with plasmid expressing Aur-A or empty vector pCS2+. Immunofluorescence staining of cells was performed as described [34] and analyzed with an Olympus BX51 microscope. For immunofluorescence staining of NF- $\mathrm{\kappa B}$ p 65 , cells were treated with $50 \mathrm{ng} /$ $\mathrm{ml}$ of TNF- $\alpha$ for 10 min prior to fixing as a positive control.

\section{MTT assay}

Tca8113 cells were incubated in 96-well plate and maintained at different doses of VX-680 for $48 \mathrm{~h}$. Myr-Akt or pUSE transfected Tca8113 cells were maintained at different doses of VX-680 for $24 \mathrm{~h}$. Cell survival was assessed as described previously [35].

\section{Flow cytometry analysis}

Cells were incubated in serum-free media with indicated drugs for $12 \mathrm{~h}$ and subjected to flow cytometry analysis as previously described [34].

\section{Annexin V assay}

Cells were treated with DMSO or VX-680 for $48 \mathrm{~h}$ prior to collecting and resuspending in binding buffer. Annexin VFITC and propidium iodide (Annexin V-FITC Apoptosis Detection Kit, Merck) were added to each sample according to the manufacturer's protocol. 4, 6-diamidino-2-phenylindole (DAPI $1 \mu \mathrm{g} / \mathrm{ml}$ ) was used to visualize nuclei. $20 \sim 25 \mu \mathrm{l}$ of cell suspension was transfered onto glass microscope slides respectively, and viewed immediately using a fluorescence microscope (Olympus BX51).

\section{Western blot assay}

Western blot assay was performed as described previously [8]. Antibodies used were mouse anti-GAPDH (Ambion), rabbit anti-Bcl-2, rabbit anti-cleaved caspase-3, mouse anti-cleaved PARP (Asp175), rabbit anti-phosphorylated Akt (pAkt, Ser473), mouse anti-phospho-GSK3 $\alpha / \beta$ (Ser 21/9, Cell Signaling), mouse anti-IкB $\alpha$ (BD), rabbit antiGSK3 $\beta$, goat anti-Akt1, rabbit anti-Bcl-xL (Santa Cruz Biotechnology) and rabbit anti-Aur-A (Upstate).

\section{Generation of stable transfection cell lines}

Myr-Akt1 and pUSE plasmids were generously provided by Xiao-feng Zhu (Cancer Center, Sun Yat-sen University). Transfections were conducted according to manufacturers' recommendations (Invitrogen). Tca8113 cell clones stably transfected with plasmid were selected in $400 \mu \mathrm{g} /$ ml G418.

\section{Transient transfection and cotransfection}

Transient transfection of Aur-A and its vector control pCS2+ or cotransfection of Aur-A or pCS2+ with siRNA against Akt 1 or its control were conducted according to manufacturers' recommendations (Invitrogen). Lysates were prepared $48 \mathrm{~h}$ after transfection. Cells were treated with API $(10 \mu \mathrm{M})$ or wortmannin $(1 \mu \mathrm{M})$ for $24 \mathrm{~h}$ prior to collecting for Western blot.

\section{RNA-mediated interference}

siRNA for downregulating Aur-A or Akt1 expression was done by the transfection of RNA oligonucleotides with lipofectamine 2000. The sequence for siRNA against AurA was AUGCCCUGUCUUACUGUCA and siRNA against Akt1 was AAGGAGGGUUGGCUGCACAAA. Lysates were prepared $36 \mathrm{~h}$ after transfection.

\section{Transwell migration assay}

Transwell assay was performed as described previously [8]. Briefly, cells were incubated in serum or serum-free media containing desired drugs for $16 \mathrm{~h}$. The migrated cells in five fields were counted, and the average of each chamber was determined.

\section{Statistics}

Statistical analysis was performed using SPSS version 13.0 (SPSS Inc., Chicago, IL, USA). The $\chi^{2}$ test and Student's ttest was used to make a statistical comparison between groups. $\mathrm{P}<0.05$ was considered statistically significant. We performed each study at least three times under identical conditions.

\section{Abbreviations}

The abbreviations used are: PI3K: phosphatidylinositol 3kinase; Aur-A: Aurora-A; TSCC: tongue squamous cell carcinoma; IGF-1: insulin-like growth factor-1; API-2: Akt/ protein kinase B signaling inhibitor-2; GSK-3: glycogen

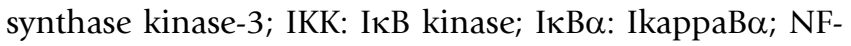
$\kappa B$ : nuclear factor- $\kappa B$.

\section{Competing interests}

The authors declare that they have no competing interests.

\section{Authors' contributions}

JY carried out protein studies, apoptosis analysis, transwell assays, immunofluorescence staining, statistical analysis and co-wrote the manuscript. MY drafted the manuscript, contributed to the study design and participated in the performed the protein studies, apoptosis analysis, transwell assays, immunofluorescence staining, statistical analysis. ZG collected the samples and reviewed specimen pathology. CB P participated in sample collec- 
tion. LP X contributed to the sample acquisition and study design. CX L contributed to reviewed specimen pathology and manuscript editing. LH W performed gene transduction and edited the manuscript. ZJ L participated in the apoptosis assay and transwell assay. MW L contributed to the sample acquisition and statistical analysis. YZ participated in immunofluorescence staining. FM Z participated in gene transduction and edited the manuscript. JX contributed to reviewed specimen pathology and the protein expression studies. DJ L participated in the design of the study and the statistical analysis. QL conceived of the study, and participated in its design and coordination and helped to draft the manuscript. All authors read and approved the final manuscript.

\section{Additional material}

\section{Additional file 1}

Cross-talk of Aur-A and PI3K pathway regulates VX-680-induced apoptosis in KB cells. Serum-starved KB cells treated with IGF-1 (I, 100 $n g / m l)$, wortmannin $(W, 1 \mu M), V X-680(V, 2 n M)$ alone or in combination for $12 \mathrm{~h}$. Cells were subjected to Western blot analysis with indicated antibodies. GAPDH served as a loading control.

Click here for file

[http://www.biomedcentral.com/content/supplementary/14764598-8-95-S1.pdf]

\section{Additional file 2}

VX-680 suppresses Tca8113 cell migration. Cells were incubated in media containing 10\% FBS with API-2 $1 \mu \mathrm{M}$ or increased dose of VX680 for $16 \mathrm{~h}$. Migration rates were quantified by counting the migrated cells in five random fields. (a) One representative of three independent experiments was shown, original magnification $\times 200$. (b) Data summarized three independent experiments, ${ }^{*} p<0.05,{ }^{*} p<0.01$.

Click here for file

[http://www.biomedcentral.com/content/supplementary/14764598-8-95-S2.pdf]

\section{Additional file 3}

Activated Akt overrides siAur-A induced cell death in TSCC cells. MyrAkt 1 or pUSE stable transfected cells were transfected with Aur-A siRNA or its scramble control. Cell survival rate was determined by MTT assay. Click here for file

[http://www.biomedcentral.com/content/supplementary/14764598-8-95-S3.pdf]

\section{Additional file 4}

Downregulation of Akt increases IKB $\alpha$ level in TSCC cells. Cells were transiently transfected with Akt1 siRNA or its scramble control. Cell lysates were analyzed for indicated proteins by Western blot. GAPDH was used as a control.

Click here for file

[http://www.biomedcentral.com/content/supplementary/14764598-8-95-S4.pdf]

\section{Acknowledgements}

We thank Yan Zhang, Jin-na Chen, Zheng-zhi Zou and Shan Huang of Quentin Liu lab for their critical commends and technical support. We thank Prof. Xiao-feng Zhu (Cancer Center, Sun Yat-sen University) for kindly providing Myr-Aktl and pUSE vector plasmids. This research work was supported by National Natural Science Foundation of China

(30772476, 30873084 and 30888003 to Q.L.), Guangdong Natural Science Fund ( 9151008901000102 to LP X) and Guangdong Medical Science Fund (B2008056 to M.Y.).

\section{References}

I. Meraldi P, Honda R, Nigg EA: Aurora kinases link chromosome segregation and cell division to cancer susceptibility. Curr Opin Genet Dev 2004, I4:29-36.

2. Liu Q, Ruderman JV: Aurora A, mitotic entry, and spindle bipolarity. Proc Natl Acad Sci USA 2006, I 03:58I I-58I6.

3. Ducat $D$, Zheng $Y$ : Aurora kinases in spindle assembly and chromosome segregation. Exp Cell Res 2004, 30 1:60-67.

4. Zhou H, Kuang J, Zhong L, Kuo WL, Gray JW, Sahin A, Brinkley BR, Sen S: Tumour amplified kinase STKI5/BTAK induces centrosome amplification, aneuploidy and transformation. Nat Genet 1998, 20:189-193.

5. Marumoto T, Zhang D, Saya H: Aurora-A - a guardian of poles. Nat Rev Cancer 2005, 5:42-50.

6. Dutertre S, Descamps S, Prigent C: On the role of aurora-A in centrosome function. Oncogene 2002, 21 :6175-6183.

7. Andrews PD, Knatko E, Moore WJ, Swedlow JR: Mitotic mechanics: the auroras come into view. Curr Opin Cell Biol 2003, I 5:672-683.

8. Guan Z, Wang XR, Zhu XF, Huang XF, Xu J, Wang LH, Wan XB, Long ZJ, Liu JN, Feng GK, Huang W, Zeng YX, Chen FJ, Liu Q: Aurora-A, a negative prognostic marker, increases migration and decreases radiosensitivity in cancer cells. Cancer Res 2007, 67:10436-10444.

9. Yang H, He L, Kruk P, Nicosia SV, Cheng JQ: Aurora-A induces cell survival and chemoresistance by activation of Akt through a p53-dependent manner in ovarian cancer cells. Int J Cancer 2006, I I 9:2304-23 I 2.

10. Vivanco I, Sawyers CL: The phosphatidylinositol 3-Kinase AKT pathway in human cancer. Nat Rev Cancer 2002, 2:489-50 I.

II. Kennedy SG, Wagner AJ, Conzen SD, Jordan J, Bellacosa A, Tsichlis PN, Hay N: The PI 3-kinase/Akt signaling pathway delivers an anti-apoptotic signal. Genes Dev 1997, I I:701-713.

12. Tokunaga E, Oki E, Egashira A, Sadanaga N, Morita M, Kakeji Y, Maehara $Y$ : Deregulation of the Akt pathway in human cancer. Curr Cancer Drug Targets 2008, 8:27-36.

13. Manning BD, Cantley LC: AKT/PKB signaling: navigating downstream. Cell 2007, I 29: | 26 |- I 274.

14. Briassouli P, Chan F, Savage K, Reis-Filho JS, Linardopoulos S: Aurora-A regulation of nuclear factor-kappaB signaling by phosphorylation of IkappaBalpha. Cancer Res 2007, 67:1689-1695.

15. Kim HJ, Hawke N, Baldwin AS: NF-kappaB and IKK as therapeutic targets in cancer. Cell Death Differ 2006, I 3:738-747.

16. Forastiere A, Koch W, Trotti A, Sidransky D: Head and neck cancer. N EnglJ Med 200I, 345: I890-1900.

17. Harrington EA, Bebbington D, Moore J, Rasmussen RK, Ajose-Adeogun AO, Nakayama T, Graham JA, Demur C, Hercend T, Diu-Hercend A, Su M, Golec JM, Miller KM: VX-680, a potent and selective small-molecule inhibitor of the Aurora kinases, suppresses tumor growth in vivo. Nat Med 2004, 10:262-267.

18. Manfredi MG, Ecsedy JA, Meetze KA, Balani SK, Burenkova O, Chen W, Galvin KM, Hoar KM, Huck JJ, LeRoy PJ, Ray ET, Sells TB, Stringer B, Stroud SG, Vos TJ, Weatherhead GS, Wysong DR, Zhang M, Bolen JB, Claiborne CF: Antitumor activity of MLN8054, an orally active small-molecule inhibitor of Aurora A kinase. Proc Natl Acad Sci USA 2007, 104:4 I06-4III.

19. Glover DM, Leibowitz MH, McLean DA, Parry $\mathrm{H}$ : Mutations in aurora prevent centrosome separation leading to the formation of monopolar spindles. Cell 1995, 81:95-105.

20. Anand S, Penrhyn-Lowe S, Venkitaraman AR: AURORA-A amplification overrides the mitotic spindle assembly checkpoint, inducing resistance to Taxol. Cancer Cell 2003, 3:5 I-62.

21. Liu Q, Kaneko S, Yang L, Feldman RI, Nicosia SV, Chen J, Cheng JQ: Aurora-A abrogation of p53 DNA binding and transactivation activity by phosphorylation of serine 2 I 5 . J Biol Chem 2004, 279:52175-52182. 
22. Taga M, Hirooka E, Ouchi T: Essential roles of mTOR/Akt pathway in Aurora-A cell transformation. International journal of biological sciences 2009, 5:444-450.

23. Dar AA, Belkhiri A, El-Rifai W: The aurora kinase $\mathbf{A}$ regulates GSK-3beta in gastric cancer cells. Oncogene 2008, 28:866-75.

24. Liu X, Shi Y, Woods KW, Hessler P, Kroeger P, Wilsbacher J, Wang J, Wang JY, Li C, Li Q, Rosenberg SH, Giranda VL, Luo Y: Akt inhibitor a-443654 interferes with mitotic progression by regulating aurora a kinase expression. Neoplasia 2008, 10:828-837.

25. Gustin JA, Korgaonkar CK, Pincheira R, Li Q, Donner DB: Akt regulates basal and induced processing of NF-kappaB2 (p I 00) to p52. I Biol Chem 2006, 28I:16473-I648I.

26. Prajapati S, Tu Z, Yamamoto Y, Gaynor RB: IKKalpha regulates the mitotic phase of the cell cycle by modulating Aurora $A$ phosphorylation. Cell Cycle 2006, 5:237I-2380.

27. Irelan JT, Murphy TJ, Dejesus PD, Teo H, Xu D, Gomez-Ferreria MA, Zhou Y, Miraglia LI, Rines DR, Verma IM, Sharp DJ, Tergaonkar V, Chanda SK: A role for IkappaB kinase 2 in bipolar spindle assembly. Proc Natl Acad Sci USA 2007, 104: 16940-16945.

28. Sun C, Chan F, Briassouli P, Linardopoulos S: Aurora kinase inhibition downregulates NF-kappaB and sensitises tumour cells to chemotherapeutic agents. Biochem Biophys Res Commun 2007, 352:220-225.

29. Massarelli E, Liu DD, Lee JJ, El-Naggar AK, Lo Muzio L, Staibano S, De Placido S, Myers JN, Papadimitrakopoulou VA: Akt activation correlates with adverse outcome in tongue cancer. Cancer 2005, 104:2430-2436.

30. Hennessy BT, Smith DL, Ram PT, Lu Y, Mills GB: Exploiting the PI3K/AKT pathway for cancer drug discovery. Nat Rev Drug Discov 2005, 4:988-I004.

31. Franke TF, Hornik CP, Segev L, Shostak GA, Sugimoto C: PI3K/Akt and apoptosis: size matters. Oncogene 2003, 22:8983-8998.

32. West KA, Castillo SS, Dennis PA: Activation of the PI3K/Akt pathway and chemotherapeutic resistance. Drug Resist Updat 2002, 5:234-248.

33. Fiskus W, Wang Y, Joshi R, Rao R, Yang Y, Chen J, Kolhe R, Balusu R, Eaton K, Lee P, Ustun C, Jillella A, Buser CA, Peiper S, Bhalla K: Cotreatment with vorinostat enhances activity of MK-0457 (VX-680) against acute and chronic myelogenous leukemia cells. Clin Cancer Res 2008, I4:6I06-6II5.

34. Huang XF, Luo SK, Xu J, Li J, Xu DR, Wang LH, Yan M, Wang XR, Wan XB, Zheng FM, Zeng YX, Liu Q: Aurora kinase inhibitory VX-680 increases $\mathrm{Bax} / \mathrm{Bcl}-2$ ratio and induces apoptosis in Aurora-A-high acute myeloid leukemia. Blood 2008, I I I:2854-2865.

35. Pan C, Yan M, Yao J, Xu J, Long Z, Huang H, Liu Q: Aurora kinase small molecule inhibitor destroys mitotic spindle, suppresses cell growth, and induces apoptosis in oral squamous cancer cells. Oral Oncol 2008, 44:639-645.
Publish with Biomed Central and every scientist can read your work free of charge

"BioMed Central will be the most significant development for disseminating the results of biomedical research in our lifetime. "

Sir Paul Nurse, Cancer Research UK

Your research papers will be:

- available free of charge to the entire biomedical community

- peer reviewed and published immediately upon acceptance

- cited in PubMed and archived on PubMed Central

- yours - you keep the copyright

Submit your manuscript here:

http://www.biomedcentral.com/info/publishing_adv.asp
BioMedcentral 